\title{
Escola Inclusiva - um olhar a partir da situação profissional dos docentes em Portugal
} Inclusive School - an approach from the professional
teachers situation in Portugal Escuela Inclusiva - una mirada desde la situación profesional del profesorado en Portugal

\author{
Marco Corriente Rosa*
}

DOI: http://dx.doi.org/10.20435/serie-estudos.v22i44.1043

\begin{abstract}
Resumo
Neste artigo, discute-se o conceito de Escola Inclusiva enquanto escola promotora de direitos humanos. Nesta abordagem em que se transmite um olhar a partir da situação profissional dos docentes em Portugal, apresentam-se os resultados parciais de um processo de pesquisa, em que se optou por uma estratégia de investigação qualitativa, descritiva e interpretativa que nos reportam para os aspetos relacionais e cooperativos no trabalho docente, para as condições de desenvolvimento profissional e para as alterações sentidas nas suas condições de trabalho, decorrentes das alterações políticas e sociais que determinaram mudanças significativas no contexto educativo. As principais conclusões sugerem que os docentes passaram a ter um importante incremento no seu trabalho que se caracteriza pela burocratização e fragmentação deste, cada vez mais orientado para a uma lógica na qual a pressão se faz sentir pela performatividade competitiva, potenciando assim a orientação da sua atividade para a sobrevalorização dos resultados escolares.
\end{abstract}

Palavras-chave

Inclusão; professorado; mudança.

\begin{abstract}
This article discusses the concept of Inclusive School as a school promoting human rights. In this approach, which looks at the professional situation of teachers in Portugal, we present the partial results of a research process, in which a qualitative, descriptive and interpretive research strategy has been chosen that refers us to the relational and cooperative aspects in the teaching work, for the conditions of professional development and for the changes felt in their working conditions, due to the political and social changes that have determined significant changes in the educational context. The main conclusions suggest that teachers have an important increase in their work, which is characterized by bureaucratization and fragmentation of the same, increasingly oriented to a logic where the pressure is felt by the competitive performativity, thus enhancing the orientation of its activity for the overvaluation of school results.
\end{abstract}

Kei words

Inclusion; teachers; changes.

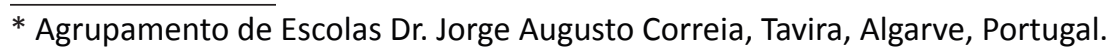




\section{Resumen}

Este artículo discute el concepto de Escuela Inclusiva como una escuela que promueve los derechos humanos. En este enfoque, que analiza la situación profesional del profesorado en Portugal, se presentan los resultados parciales de un proceso de investigación en el que se ha elegido una estrategia de investigación cualitativa, descriptiva e interpretativa que nos remite a los aspectos relacionales y cooperativos de la enseñanza, por las condiciones de desarrollo profesional y por los cambios experimentados en sus condiciones de trabajo, debido a los cambios políticos y sociales que han determinado cambios significativos en el contexto educativo. Las principales conclusiones sugieren que los docentes tienen un importante incremento en su trabajo, que se basa en la burocratización y fragmentación, cada vez más orientados para una lógica donde la presión se siente por la performatividad competitiva, potenciando así la orientación de su actividad para la sobrevaloración de los resultados escolares.

\section{Palabras clave}

Inclusión; profesorado; cambio.

\section{INTRODUÇÃO}

Equacionar a Educação Inclusiva a partir de uma visão holística da escola éa intenção desta comunicação, que coloca, na centralidade dessa problemática, a situação profissional do professorado e a relevância do seu papel no desenvolvimento e aprofundamento desse paradigma, sempre inconcluso.

A conceção de práticas e atitudes profissionais que determinam uma Escola que se caracterize por uma vertente Inclusiva está subjacente à forma como esta se organiza e àquilo que são as condições de exercício profissional dos docentes, designadamente no que diz respeito às suas condições de trabalho, às relações profissionais que se estabelecem, à componente cooperativa do trabalho que se desenvolve entre pares e às condições para um desenvolvimento profissional, assente na aquisição de novas competências que vão ao encontro dos desafios que se colocam à Escola e à profissão.
As novas realidades discursivas procuram trazer o professorado para o centro desta discussão com uma retórica que se repete quanto à necessidade de valorizar o seu papel, a sua autonomia, ou a sua imagem social, porque lhes cabe formar as novas gerações em conformidade com as exigências do futuro, da sociedade da informação, do desenvolvimento económico ou qualquer outra razão que esteja na moda. No entanto, como referiu António Nóvoa ${ }^{1}$, os discursos e as práticas, muitas vezes, revelam mundos distintos, construindo uma ideia que não corresponde à intencionalidade declarada.

Assim, os resultados do estudo que realizámos (ROSA, 2016a) permitiu-nos conhecer, através de uma abordagem investigativa de caráter qualitativo, narrativo e interpretativo, o processo

${ }^{1}$ Em palestra proferida na Faculdade de Educação da Universidade de São Paulo, no dia 20 de maio de 1999. 
complexo, multifacetado, idiossincrático e contextual com o qual os profissionais docentes se confrontam no seu trabalho, bem como os dilemas, as contradições e os paradoxos que daí decorrem e que determinam a sua predisposição para dar resposta a uma multiplicidade de exigências.

É dentro dessa dialética que se apresentará uma reflexão sobre o conceito de inclusão, as atitudes e as contradições que resultam das evidências que os resultados do estudo sobre a situação profissional do professorado em Portugal, designadamente quanto aos impactos que os fatores políticos e sociais recentes tiveram na profissão e à forma como essas influências podem condicionar as atitudes potenciadoras de uma escola (mais) inclusiva. Assume-se assim, o pressuposto de que uma verdadeira escola inclusiva só é possível com um corpo docente empenhado, motivado e valorizado.

\section{ABORDAGEM METODOLÓGICA - OBJETIVOS, METODOLOGIA E PARTICIPANTES}

O Enfoque no processo de recolha de dados incidiu em dois cenários muito concretos que se desenvolveram em distintos momentos. Assim, procurámos conhecer e compreender os fatores objetivos e subjetivos que contribuíram para operar uma transição na identidade dos docentes, através de uma profunda revisão do Estatuto da Carreira Docente (ECD) e, por outro lado, na abordagem que se efetuou à crise económica e financeira, com cortes consideráveis na educação, que, com medidas muito concretas, implicaram a deterioração da qualidade do processo educativo e uma dificuldade acrescida às condições de trabalho e de vida do professorado.

Os dados foram recolhidos junto de docentes que exercem a sua atividade profissional no sistema de ensino público em Portugal, a Ministra da Educação do XVII Governo Constitucional e os líderes das duas Federações Sindicais que representam a profissão docente, designadamente da Federação Nacional dos Professores (Fenprof) e da Federação Nacional da Educação (FNE). Para o efeito, realizámos um total de 27 entrevistas e dois grupos de discussão que implicaram o envolvimento de mais 13 docentes, num total de 40 protagonistas.

A utilização dessas técnicas permitiu-nos recolher um manancial de informação, a partir da qual se pretendeu chegar a um entendimento profundo e, até, a uma dimensão subjetiva dos participantes (seja no plano individual ou coletivo) e dos fenómenos, dirigindo a intenção da pesquisa para grupos reduzidos, mas a serem intensamente estudados (DENZIN; LINCOLN, 2006).

Nesse caso, considerou-se pertinente seguir uma metodologia de investigação qualitativa, interpretativa e descritiva, pois entendeu-se que seria a mais adequada para compreender os processos e os fenómenos inerentes à problemática da investigação que versa sobre a situação profissional do profes- 
sorado em Portugal. Assim pretendemos efetuar uma investigação acerca "das ideias, da descoberta dos significativos inerentes ao próprio indivíduo, já que ele é a base de toda a indagação" (PACHECO, 1995, p. 16).

O paradigma interpretativo assenta em posições fenomenológicas e interpretativas, assumindo uma importância ainda maior quando se trata de investigações que incidem sobre os pensamentos de sujeitos como refere Geertz (1973 apud BOGDAN; BIKLEN, 1994). O que os fenomenologistas enfatizam é a componente subjetiva do comportamento das pessoas. Tentam penetrar no mundo conceptual dos indivíduos, para o compreender, de que forma o constroem e quais os significados que se atribuem para os acontecimentos das suas vidas quotidianas.

A dimensão fenomenológica parte do mundo conhecido, do qual se faz uma análise descritiva com base nas experiências vividas. Do mundo conhecido e das experiências intersubjetivas obtêm-se sinais e indicações para interpretar a diversidade dos símbolos, a partir dos quais é possível interpretar os processos e estruturas sociais em curso (HUSSERL, 1982).

O processo de análise das entrevistas e dos grupos de discussão foi-se desenvolvendo através de um método dedutivo, a partir dos tópicos que elaborámos e também, num processo indutivo, atribuindo valor aos dados que iam imergindo, em duas fases, numa análise vertical (MILES; HUBERMAN, 1994), a partir do discurso de cada participante, e uma análise horizontal ou comparativa, com recurso a comparações constantes (GLAUSER; STRAUSS, 1967), para encontrar temas comuns e distintivos, procurando triangular os dados destas diferentes técnicas qualitativas de recolha.

\section{INCLUSÃO - CONCEITO, ATITUDES E CONTRADIÇÕES}

O movimento por uma escola inclusiva tem avanços significativos na década de 1990, com um marco inquestionável, a Declaração de Salamanca, em 1994. A emergência desse paradigma no contexto educativo consiste em acrescentar à integração física de alunos com Necessidades Educativas Especiais (NEE) nas escolas públicas, o envolvimento académico nas classes regulares destas. Assume-se, assim, com clareza, que a heterogeneidade interpessoal é um fator que promove o desenvolvimento de comunidades escolares mais complexas, acreditando-se que dessa complexidade surja uma maior riqueza e tolerância.

A inclusão apresenta-se como um passo em frente para além da presença física e social do aluno nas escolas como era suposto no paradigma da integração, mas também com a participação efetiva na interação com os seus pares, com direito a intervenções e interações com os docentes e participação ativa na comunidade escolar. Pretende-se, portanto, que todos os alunos aprendam juntos respeitando a diversidade. Correia (2001) acrescenta que a diversidade 
pode ser definida como o conjunto de diferenças individuais, que, em muitos casos, devem ser objeto de intervenções adequadas e individualizadas, referindo-se obviamente a apoios educativos adequados.

A inclusão vem questionar as políticas e a organização da educação especial e regular, mas também o conceito de integração - o chamado mainstreaming . A inclusão refere-se à vida social e educativa de todos os alunos. Devem ser incluídos nas escolas regulares e não somente colocados na corrente principal. 0 vocábulo integração, muitas vezes ainda referido em meio escolar, é confundido frequentemente com os princípios da educação inclusiva e, em muitos casos, traduz uma representação equivocada da educação inclusiva, assim como o processo inverso também é válido, isto é, muitas vezes fala-se em inclusão, trazendo à tona, do discurso, das atitudes e das representações, o paradigma da integração.

Não menos importante que as terminologias e as suas contradições é a discussão que se deve centrar nas atitudes, nas políticas e nas condições concretas para desenvolver e aprofundar práticas, que, do meu ponto de vista, sempre e constantemente, possibilitarão margens de reflexão e de melhoria, pois devemos ter em conta que a própria realidade social, ela mesma, é dinâmica e, portanto, exigirá respostas à altura dessa mesma característica de contínua transformação. Por outro lado, devemos ter em conta que o termo inclusão é amplamente difundido, ainda que o conceito não seja totalmente consensual do ponto de vista académico e social.

A perspetiva inclusiva conduz-nos a uma rutura com as abordagens tradicionais e abre novos desafios a toda a comunidade educativa, as quais apontam para que todos os alunos, independentemente das suas diferenças, tenham uma igualdade de oportunidades na sociedade.

Em trabalho de investigação realizado anteriormente (ROSA, 2005), foi possível concluir, a partir da análise dos dados, que a inclusão se enquadra em conceções que se baseiam na igualdade de direitos e oportunidades, na participação e no respeito pela diferença, mas também se salienta o facto de se encontrar grandes dificuldades na conciliação de um trabalho de qualidade para alunos com NEE integrados em turmas regulares, emergindo a necessidade de um trabalho individualizado de reforço, que não será mais do que criar condições de igualdade para todos os que, por alguma razão, se encontrem em situação de maior vulnerabilidade.

Foi referido também, no mesmo estudo, que a realidade conceptual está longe de uma realidade prática, pois torna-se difícil à escola responder aos pressupostos da inclusão, uma vez que, não sendo um elemento estanque da sociedade, é altamente permeável ao contexto sociopolítico, não podendo alhear-se à mercantilização dos serviços públicos básicos, sobretudo na saúde e na educação, da degradação 
das condições de vida das comunidades proporcionadas pela crescente onda de políticas de globalização neoliberal, cujo lema dominante é limitar a despesa do estado nos serviços públicos colocando em causa os direitos, acentuando as diferenças individuais e aumentando as assimetrias sociais. Consideramos, por isso, que o que está em causa são os direitos sociais e que a sua perda representa uma regressão civilizacional, o que, aliás, foi uma dura realidade sentida na sociedade portuguesa e que se intensificou sensivelmente a partir de 2011, com um programa de intervenção externa com grandes impactos no sistema educativo em Portugal (BENAVENTE et al., 2015; ROSA, 2016a), como teremos possibilidade de explanar mais adiante.

Passadas praticamente três décadas desde a década de 1990, período marcante em que o movimento pela Escola Inclusiva teve um importante incremento, podemos afirmar, em retrospetiva, que os princípios humanos e progressistas da Educação Inclusiva, enquanto importante alicerce da coesão social, têm sido amplamente postos em causa por aquilo que tem sido uma transposição do discurso e da lógica dos mercados para as políticas educativas.

A educação tem sido alvo de um processo ideológico que se baseia numa narrativa vaga e incerta que oscila entre vocábulos como o mérito, a excelência e o rigor para justificar a mensuração enquanto critério de qualidade numa lógica de prestação de contas (performativity), impregnando uma crença e uma orientação mercantilista que se tem consubstanciado nas múltiplas chamadas de atenção para os constantes apelos às novas necessidades económicas, que, dessa forma, se tem exprimido por uma subordinação das políticas educativas às demandas dos mercados, uma entidade desprovida de rosto e de dimensão humana, com agendas muito próprias, que nos trazem um conceito de progresso e de nova modernidade baseadas em políticas de baixos salários, exploração, precariedade e erosão dos direitos fundamentais, colocando em causa direitos humanos. Dessa forma, as novas exigências interpretadas por políticas europeias, na maior parte dos casos, com pressões muito acentuadas sobre os governos dos estados membros, têm-se pragmatizado pelo contraponto com as exigências de uma escola e de uma sociedade promotoras de inclusão, que se refletem no abandono de preocupações no exercício, desenvolvimento e aprofundamento de práticas democráticas e de cidadania, pois o que interessa é produzir trabalhadores dóceis, que se deixem explorar, numa lógica de conformismo, abdicando da sua dimensão de cidadãos, levando a que a sociedade atual se veja confrontada com uma crescente onda de analfabetismo cívico.

\section{O CONTEXTO}

Os aspetos contextuais são decisivos no desenvolvimento deste estudo, pois determinam, em grande parte, os estados de alma dos protagonistas em 
análise e interferem diretamente com os aspetos subjacentes às mudanças operadas. Assim passamos a caracterizar dois momentos, a revisão do Estatuto da Carreira Docente (ECD), um processo que se iniciou em 2006, e o programa de assistência financeira externa, com medidas orçamentais restritivas que determinaram cortes em importantes áreas, neste caso concreto com fortes repercussões no sistema educativo.

O mais recente processo de alteração do ECD, que se inicia em 2006 e que culmina com o DL n. 15/2007 de 19 de janeiro, implicou uma tremenda revolução no ECD, praticamente desfigurando-o, ou melhor dizendo, transfigurando a profissão. Um processo conturbado e nada pacífico para o professorado Português, pois, inclusivamente, esse dia foi decretado como dia nacional de luto dos professores e educadores, pela Plataforma Sindical, uma plataforma histórica para onde convergiram todos os sindicatos de docentes.

De acordo com Stoleroff (2007), o conflito em torno do ECD, destaca-se pela continuidade e intensidade da mobilização dos docentes e pela unidade sindical, sobressaindo da reforma generalizada também noutros setores da Administração Pública. Segundo o mesmo autor, a importância desse conflito deriva da dimensão desse grupo profissional, do alcance e da abrangência das reformas, das características particulares dos processos de negociação e do papel da Educação no desenvolvimento do País.
O movimento muito amplo e claramente maioritário em torno da defesa e afirmação da profissão docente assume um contorno de movimento social muito importante para a afirmação de uma identidade profissional que foi decisiva para provocar recuos por parte do Ministério da Educação (ME) e conquistas parcelares por parte do professorado, uma vez que estas não significaram um retrocesso ao ponto de partida.

Muito embora os resultados do processo de investigação demonstrem que essas conquistas foram parcelares, contudo não foram incipientes, tendo em conta a situação anterior, os docentes e os seus sindicatos valorizam-nas, nomeadamente pelo fim de uma carreira hierarquizada e a simplificação de um processo de avaliação que veio alterar todo o mapa relacional e cooperativo no trabalho docente. Os recuos verificados decorreram de processos de grande unidade e resistência protagonizados pelos docentes e pela plataforma sindical dos professores que, só dessa forma, puderam forçar o diálogo e a negociação com o ME liderado por Maria de Lurdes Rodrigues.

A partir do ano de 2011, mais concretamente, a austeridade imposta por instâncias internacionais, a que se aliou um governo de direita, desencadeou medidas devastadoras nas áreas sociais do estado (BENAVENTE et al., 2015) e, no caso que abordamos presentemente, no sistema educativo e na profissão docente.

As tendências neoconservadoras e neoliberais das políticas em curso são sintetizadas por Benavente et al. 
(2015, p. 19), quando se refere que há elementos no contexto mundial que favoreceram e favorecem políticas de retrocesso à Escola tradicional, "a escola das notas e dos exames, da seleção e da exclusão". Uma leitura feita a partir do discurso paradigmático do Ministério de Educação e Ciência, liderado por Nuno Crato, um Ministro com uma postura conservadora e que transporta a Escola para uma linguagem de um passado de ditadura fascista, que teve o seu ocaso em abril de 1974. As medidas e o discurso sobre as políticas educativas em Portugal trazem fortes reminiscências a tempos de outrora.

O recurso a mecanismos sofisticados de controlo passa a ter uma ligação muito direta entre objetivos e resultados obtidos por valores mensuráveis, através de diversos instrumentos, resultados de exames, rankings, recurso a meios estatísticos e comparabilidades. Com a imposição de tendências e prioridades, normaliza-se, em meio escolar, a componente seletiva assentes no pressuposto da inevitabilidade e das desigualdades sociais, fomentando-se o individualismo e a competição como motores do sucesso pessoal (BÓıA, 2003).

Uma das possíveis leituras do processo de gestão da crise em Portugal é que aquela se transformou num instrumento de dominação, pois serve para legitimar decisões políticas e económicas que amputam nos cidadãos o direito um exercício de participação que os define enquanto tal, afastando-os de todas as possibilidades de decisão.
Nunca como agora o desígnio, assumido pelo país como estado membro da UE, da construção de um espaço europeu comum de educação nos impôs uma posição tão claramente periférica, subalterna e tão exposta a deficit democrático. $\mathrm{O}$ alinhamento dos decisores políticos com a agenda hegemónica supranacional encontra na crise um aliado na defesa de medidas que nos conduzem perigosamente a uma regressão social. (BENAVENTE et al., 2015, p. 50-51).

Segundo Santos (2007), a tensão entre capitalismo e democracia não é facto recente. Em grande medida, a função do Estado numa sociedade capitalista seria tentar equalizar as demandas de lucro que o sistema capitalista exige, e as necessidades dos cidadãos. Enquanto os grupos marginalizados lutam por inclusão social, as empresas disputam espaço dentro do mercado de bens e serviços. Essa dinâmica deve ser administrada pelo Estado através do contrato social, na medida em que é esse mesmo contrato que "regula a tensão entre regulação social e emancipação, entre ordem e progresso" (SANTOS, 2007, p. 86).

As demandas políticas que advêm das exigências da economia capitalista em crise entram pela porta da escola e instalam-se assumindo a forma e o conteúdo dos processos de subordinação hierárquica (BENAVENTE et al., 2015).

De acordo com Rosa (2016a), os valores da execução orçamental, que 
rondavam os $5 \%$ do Produto Interno Bruto (PIB), baixaram para $4 \%$ do PIB. Essa redução implicou uma redução de recursos a diversos níveis e com fortes impactos na profissão docente, pois, durante período de 2011 e 2015, o número de docentes nas escolas reduziu-se em cerca de $34 \%$. Essa redução foi feita através da operacionalização de medidas muito específicas, das quais destacamos com especiais efeitos:

a) a reorganização da rede escolar, encerrando escolas de pequena dimensão e centralizando em grandes unidades e a fusão de agrupamentos de escolas já existentes, um fenómeno que ficou conhecido por Mega-Agrupamentos;

b) o aumento do número de alunos por turma;

c) uma reorganização curricular que reduziu as áreas de expressão, potenciando a disciplina de Matemática e de Português.

A essas medidas de corte, juntam-se também os cortes nos salários. Os impactos sentidos na dimensão pessoal e profissional da classe docente são tremendos, levando a que os sentimentos sejam pontuados pelo desencanto com a profissão, pelo desgaste acentuado e pela vontade de a abandonar, por via de rescisão ou mesmo por aposentação, conforme os casos. Também é notório o aumento do risco para doenças no âmbito da saúde mental, pois ao desgaste que se sente junta-se o facto de existirem menos docentes no sistema, com as consequências de uma maior precariedade nas condições de trabalho e de vida e uma intensificação e complexificação do trabalho docente, que é desenvolvido numa lógica mercantilista de obtenção de resultados, valorizando-se mais o produto que o processo, não levando em linha de conta as condições de partida.

\subsection{Aspetos relacionais e cooperativos no trabalho docente ${ }^{2}$}

A análise dos vários quadros legais que se foram sucedendo sugere alterações na forma dos docentes trabalharem e se relacionarem entre si. Os docentes na sua generalidade concordam que as relações laborais e o trabalho cooperativo foram comprometidos pelas novas demandas, sentidos e significados concretos que dão um pragmatismo aos efeitos das mudanças operadas, particularmente, na forma como sentem e interpretam as suas funções, a qual, em muitos casos, choca com as suas expetativas e motivações iniciais, aquelas que outrora os levaram a optar pela escolha da profissão.

A generalidade dos participantes consideram que as relações profissionais e, nomeadamente, o trabalho cooperativo ficaram comprometidos pelas alterações operadas na carreira, dando ênfase às relações de subordinação hierárquica, que assumiram um importante relevo e tiveram o seu expoente máximo de conflito nas alterações ao processo de

${ }^{2}$ Os nomes atribuídos aos excertos discursivos dos participantes, que serão introduzidos de aqui em diante, são fictícios. 
avaliação de desempenho na vigência da Ministra da Educação, Maria de Lurdes Rodrigues, a partir de 2006, incrementando-se uma componente competitiva que é o contraponto da solidariedade, da entreajuda e da cooperação, aspetos essenciais para um exercício da docência numa vertente (que se pretende) reflexiva.

Foram ainda apontados comentários que sugerem um défice democrático que nos permite inferir que as relações de igualdade entre pares foram postas em causa por uma relação, então, hierarquizada. São feitas várias referências à democracia como uma prática que se transmite no seu pleno exercício, dizendo no fundo que a escola não a pode transmitir se não a pratica. Uma reflexão que urge lançar no atual panorama educativo em Portugal.

O trabalho cooperativo é uma importante vertente para o desenvolvimento profissional e lança o desafio e a responsabilidade social que cada docente tem que assumir na defesa da sua identidade profissional.

A saída para o desenvolvimento profissional na escola. É a força da convicção do que é ser professor e cada vez mais, cada um de nós, cada um dos professores, chamar para si essa função, aquilo que está inerente a essa função... e não se esquecer... e passar a palavra, sempre que possa fazê-lo, passar a palavra, embora possa parecer passar por "chato", mas tem que ser (Almiro).
Uma referência incontornável é também ao clima de subserviência em relação ao regime de gestão e direção das escolas. Nesse âmbito, são referidas expressões como o medo que se sente e o cuidado exagerado para não afetar nenhuma suscetibilidade do poder.

Se já havia pouca democracia na escola, agora pode-se dizer que não há nenhuma. Não há uma prática democrática e fala-se na importância da democracia, mas se não existe a prática, logo... É uma coisa metafísica, não existe! É abstrata, isso é muito negativo (Inês).

\subsection{Condições para o desenvolvimento profissional}

As condições para cada docente desenvolver o seu trabalho e se desenvolver profissionalmente são uma questão central na classe docente. Os participantes são unânimes ao considerar que atualmente as condições para o seu desenvolvimento profissional não são as melhores, atribuindo que a inexistência dessas condições passa por várias razões, concretamente as que a seguir apontamos, que vieram à luz da análise efetuada aos seus segmentos discursivos, relativamente a esses aspetos em particular.

A precariedade e a falta de segurança, no que diz respeito ao vínculo laboral é um dos obstáculos apontados às condições favoráveis para o desenvolvimento profissional, pode-se dizer que há aqui um sentimento de instabilidade 
emocional e profissional associada a esse fator.

Alguma quebra de solidariedade entre pares, que resulta da introdução de uma maior competitividade entre os docentes é amplamente referido, uma vez mais as relações de cooperação assumem-se como fator promotor do desenvolvimento profissional.

Uma das coisas que nos faz melhores profissionais é as discussões de grupo, entre colegas do mesmo grupo. A partilha de dúvidas, a partilha de questões, faz com que nós fiquemos melhores também (Roberta).

Uma vez mais, o processo de avaliação do desempenho é apontado, desta vez como entrave às condições para o desenvolvimento profissional, pois toda a burocracia que tal processo envolve representa um acréscimo de trabalho que, inevitavelmente, tem como consequência um incremento de fadiga, para além do dispêndio de tempo. Dessa forma, a fadiga e o desgaste são a consequência de um trabalho cada vez mais árduo e multifacetado para responder às exigências do sistema, constituindo-se como uma importante barreira ao desenvolvimento profissional.

As pessoas estão, psicologicamente, um bocado fragilizadas $e$ tendem talvez a não investir tanto em algumas coisas porque estão cansadas. Existe um grande cansaço entre os colegas (Carla).
A falta generalizada de recursos que se vai sentindo cada vez mais, resulta da acumulação de várias imposições orçamentais e já começam a ser um entrave, pois também limitam o trabalho dos docentes.

Por fim, a oferta formativa, que é considerada escassa e deficitária, também é um fator que os docentes consideram constituir um obstáculo ao seu desenvolvimento profissional, pois trata-se de uma profissão em que se sente uma necessidade permanente de atualização pedagógica e científica,

A formação contínua [...] é importante para o nosso desenvolvimento, porque as coisas estão sempre a evoluir e estão sempre a mudar e acho que nós também temos que entrar nessa evolução, a formação é importante, até porque tu podes fazer uma formação, outro colega faz outra formação, $e$ depois encontram-se e acaba por haver a partilha dos conhecimentos de uns e de outros, esclarecendo dúvidas (Álvaro).

\subsection{Condições de trabalho}

A alteração das condições de trabalho surge como assunto incontornável quando se trata de definir alterações ao ser e sentir do professorado. Assim, decorrente de um conjunto de medidas, surgem consequências imediatas com um impacto determinante na fragmentação do trabalho docente e na sua intensificação. 
O aumento do número de alunos por turma, que passou de 26 para 28 e, mais recentemente, de 28 para 30 , é uma das principais razões de atribuição à deterioração das condições de trabalho.

$O$ aumento do número de alunos por turma. A nível de Língua Estrangeira, na aprendizagem, é impossível. É fingir que estamos a ensinar, com um número tão grande de alunos por turma, não se consegue... Só fazendo o pino. Há muito mais dificuldade (Nádia).

Um exemplo bem ilustrativo das dificuldades sentidas por essa participante, que neste caso concreto se refere à dificuldade em ensinar uma língua estrangeira com mais alunos. Acreditamos que esse fator traz claros prejuízos para a aprendizagem dos alunos, uma vez que se sobrevalorizam os aspetos de natureza burocrática, em detrimento dos aspetos pedagógicos.

Uma turma do ensino secundário, de artes, com 30 alunos, num trabalho, com folhas largas, para fazer uma maquete, não cabíamos dentro da sala. 30 alunos numa turma de Artes do Secundário é impensável. A gente faz, mas não dá a atenção que deve dar, e alguns alunos perdem-se (Reinaldo).

Mais uma referência às dificuldades sentidas, neste caso por um participante que se dedica ao ensino de artes visuais, que refere dificuldades na organização do espaço físico, pelo número de alunos, mas também e, uma vez mais, pelo acompanhamento pedagógico que se perde, nomeadamente, no acompanhamento de alunos com mais dificuldades.

Dentro desses exemplos há duas evidências, por um lado, o acréscimo de desgaste a que os docentes estão sujeitos, pelo facto de trabalharem com mais alunos e, por outro lado, a constatação que a qualidade pedagógica diminui, com consequências para as aprendizagens dos alunos.

O preenchimento de papéis são uma treta, mas é assim, sou professor, sei ler e escrever $e$ preencho os papéis que eles quiserem. $O$ problema é que depois fico demasiado tempo a tratar (...) dos papéis e não faço o que devia fazer, que é ter uma relação com os meus alunos cordial, colaborativa, estimulante ou estimuladora. Isso é que era importante. (Filipe).

A fragmentação do trabalho docente, com o incremento de tarefas díspares também é um dos indicadores que os participantes apontam, como aliás já foi referido anteriormente quando mencionámos o incremento de tarefas burocráticas, mas não só, pois, a tendência que se tem verificado, em que cada docente tem mais turmas, mais níveis de escolaridade e uma maior diversidade de trabalho, no âmbito de apoios e tutorias, faz com que o tempo para a sua formação e para a preparação do seu trabalho letivo seja amplamente colonizado. 
Eu sinto que há uns anos atrás eu tinha tempo para falar com os meus colegas, encontrávamo-nos, e que hoje mal nos cruzamos. Já chegou a acontecer, há tempos atrás, encontrar um colega, quase no final do ano e chegarmos à conclusão que, estando na mesma escola, não nos cruzamos e nem nos vimos (Fernanda).

A forma como os docentes se encontram menos disponíveis para o trabalho com os seus pares, portanto cooperativo, ou mesmo para tratar de assuntos profissionais e para discussões que podem ser enriquecedoras, no sentido da partilha, é notória e, várias vezes, mencionada. Uma novidade relativamente recente também decorre da amplificação do espaço escolar a outros estabelecimentos, com a constituição dos referidos Mega-Agrupamentos.

A nossa escola era pequena $e$ passou a uma escola grande. A mobilidade entre escolas também é uma coisa que não agrada a ninguém (...). Desenvolvo trabalho em duas escolas, com vários ciclos de ensino, 0 que também acho prejudicial ao trabalho, uma pessoa tem que avaliar vários níveis e isso aumenta-lhe as dificuldades, essencialmente em termos de tempo, porque obriga a gastar mais tempo com a avaliação dos alunos e obriga a passar mais tempo na escola porque, em horas mortas, tens que transitar entre escolas. Se for preciso tens que te deslocar duas vezes à mesma escola, isto é, o tempo que podias estar a dar aulas ou a preparar alguma coisa, andas de um lado para o outro (Nuno).

A intensificação do trabalho acaba por ser uma consequência das novas demandas, como se pode constatar por todas as razões apontadas pelos participantes as quais, segundo estes, constituem-se como fatores que agravam o desgaste e a fadiga.

Sou professor de Educação Musical, estou com turmas das $8.20 h$ até às $16 h$, onde estou sempre sujeito a uma grande carga sonora, porque é disso que se trata, vou ter perturbações do sono, os níveis de stress vão aumentar, a minha capacidade auditiva, com o tempo, vai diminuir. Vou ter problemas de tensão arterial, vou ter problemas de concentração, isto está tudo estudado pela OMS. Isto é válido para mim e para qualquer outra pessoa que esteja sujeita às mesmas condições. Considero que esta profissão é de desgaste e, com a intensificação do trabalho, esse desgaste ainda é mais potenciado. Havia medidas do anterior ECD que defendiam mais os profissionais, nomeadamente com o alívio da carga horária a partir de determinada idade (Domingos). 
Uma referência clara, num exemplo ilustrativo, de intensificação da carga de trabalho, neste caso concreto, um docente de Educação Musical, sujeito a uma estimulação auditiva constante e intensa.

Para terminar, surge mais um exemplo da intensificação de trabalho e da sua influência na vida particular, designadamente, no tempo de descanso e na vida familiar.

A minha vida social nunca foi muito intensa, mas cada vez é menor, porque o ter disponibilidade para me encontrar com familiares ou amigos, etc... é cada vez mais raro, depois, inevitavelmente, o meu descanso, não consigo estar um dia sem trabalhar para a escola (Clara).

\section{CONCLUSÕES}

Uma profissão docente que reclama mais autonomia para dar uma resposta mais congruente aos desafios cada vez mais complexos que Ihe são colocados passou a ter um importante incremento no seu trabalho que se caracteriza pela burocratização e fragmentação deste, cada vez mais orientado para a uma lógica em que a pressão se faz sentir pela performatividade competitiva, potenciando assim a sobrevalorização dos resultados numa lógica de valorização através de instrumentos de precisão mensurável, relegando, para um outro plano, processos que visem à capacitação da Escola no sentido de combater a exclusão social, construir exemplos de boas práticas na inclusão, de promover o sucesso escolar e de democratizar o acesso às formas elaboradas de cultura. Muito embora esses pressupostos adornem os discursos oficiais, poderemos mesmo afirmar que esbarram com uma realidade bem difusa, sobretudo se tivermos em conta as condições em que os docentes exercem o seu trabalho.

O conceito de inclusão está longe de ser consensual. Existem bons e valiosos contributos para a sua definição. Existe uma riqueza retórica que contrasta com a pobreza da generalidade dos contextos educativos e sociais para a colocar em prática, encontrando-se argumentos que a transportam para as dimensões da utopia ou do romantismo. A inclusão é um ingrediente para sociedades mais ricas e tolerantes e um pilar essencial da democracia. Esta, para ser aprendida, tem que ser praticada e vivida, assim o dizia John Dewey há cem anos, na sua obra Democracia e Educação. A inclusão alimenta-se e cresce a partir da convivência e da participação. Em meio escolar, os professores são um elemento chave e indispensável para a construção de uma escola inclusiva. Acreditamos, por isso mesmo, que as condições em que exercem o seu trabalho são determinantes para o desenvolvimento de competências e metacompetências essenciais para a sua efetivação e para a sua promoção. Só com Escolas promotoras de inclusão podemos ter sociedades inclusivas e vice-versa. 
Um dos principais meios para dar resposta aos desafios da escola atual é a aposta na formação inicial e ao longo da vida dos docentes. Para além desses aspetos, é essencial o tempo, que deve ser disponibilizado para que se possam entreajudar e explorar aspetos da sua prática pedagógica num clima positivo, saudável, evolutivo e reflexivo. A formação, que pode ser em ambientes formais, mas também a partir da própria prática em ação, assim como a disponibilidade de tempo são muito importantes e pertinentes, pois permitem identificar e partilhar os sucessos, os insucessos e as inquietações próprias do processo educativo.

As implicações emocionais, na forma como é vivida e sentida a profissão, são pontuadas por sentimentos como o desencanto, a desmotivação e a revolta. Estes decorrem de um profundo desacordo com as políticas educativas que têm originado um processo de erosão do estatuto social da profissão. A descrição dos sentimentos que se foi desocultando, a partir da análise efetuada, permite compreender que os docentes vivem a sua vida profissional de forma fragmentada, com extremos que se deslocam entre a paixão e o desencanto (ROSA, 2016b).

A enorme ambiguidade e avaliação pública a que o trabalho dos docentes se encontra sujeito exerce sobre estes uma pressão que os situa entre dois extremos, por um lado, a luta permanente para ampliar a sua margem de autonomia no processo de trabalho e, conse- quentemente, o seu poder e prestígio, e por outro lado, a rigidez das suas cúpulas hierárquicas, como sejam os órgãos de direção e gestão das escolas.

As lideranças das escolas encontram-se cada vez mais distantes de processos de gestão democrática. Lima (2014) caracteriza-as como uma pós-democracia gestionária, isto é, uma gestão centrada nos resultados escolares e numa racionalização das redes escolares, a par de processos de grande deterioração das condições de trabalho nas escolas e da (re)centralização do poder. Segundo o autor, essa situação é motivada por políticas de austeridade e de ajustamento económico, como as que têm ocorrido no sul da Europa, designadamente em Portugal. Na sua perspetiva, o governo democrático das escolas surge como uma preocupação deslocada, fora de tempo e das prioridades políticas, mas também, e sobretudo, associada ideologicamente a uma irresponsabilidade, em termos de gestão racional, eficaz e eficiente dos estabelecimentos de ensino. A Escola, nos seus aspetos organizacionais, fica assim praticamente expurgada dos processos de eleição, de colegialidade e de participação nas decisões, componentes que, para os docentes, são imprescindíveis ao desenvolvimento de processos de participação assentes em princípios democráticos.

Para finalizar, um convite à reflexão e um dilema. Fará sentido falar em Escolas Inclusivas sem debater as situações atuais de organização escolar, dos currículos, no que diz respeito à sua 
conceção e prioridades e, finalmente, dos docentes, da sua formação e das condições em que desenvolvem o seu trabalho. Poderá a Escola ser inclusiva para os que a frequentam se não for inclusiva para os que nela trabalham, no que diz respeito ao seu acolhimento, valorização profissional e social e na implicação da sua participação nas decisões?

\section{REFERÊNCIAS}

BENAVENTE, A. et al. Crise, austeridade e educação em Portugal (2011-2014). Investigar em Educação, Ila série, n. 3, p. 49-62, 2015.

BOGDAN, R.; BIKLEN, S. Investigação qualitativa em educação. Uma introdução à teoria e aos métodos. Porto, Portugal: Porto Editora, 1994.

BÓIA, J. Educação e sociedade. Neoliberalismo e os desafios do futuro. Lisboa: Edições Sílabo, 2003.

CORREIA, L. M. Educação inclusiva ou educação apropriada. In: RODRIGUES, D. (Org.). Educação e diferença: valores e práticas para uma educação inclusiva. Porto, Portugal: Porto Editora, 2001. p. 125-142.

DENZIN, N.; LINCOLN, Y. Planejamento da pesquisa qualitativa - teorias e abordagens. Porto Alegre, RS: Artmed, 2006.

GLAUSER, B.; STRAUSS, A. The discovery of grounded theory: strategies for qualitative research. Chicago: Aldine, 1967.

HUSSERL, E. La Idea de la fenomenología. Madrid: Fondo de Cultura Económica de España, 1982.

LIMA, L. A gestão democrática das escolas: do autogoverno à ascensão de uma pós-democracia gestionária? Eduação \& Sociedade, Campinas, SP, v. 35, n. 129, p. 1067-1083, out./dez. 2014.

MILES, M.; HUBERMAN, A. Qualitative data analysis: an expanded source book. London: Sage Publications, 1994.

PACHECO, J. O pensamento e a ação do professor. Porto, Portugal: Porto Editora, 1995.

ROSA, M. A situação profissional do professorado em Portugal - análise às transições mais recentes (2007-2015). 2016. Tese (Doutorado em Educação) - Universidad de Huelva, Huelva, Espanha, 2016a. Disponível em: <http://rabida.uhu.es/dspace/bitstream/ handle/10272/12084/A_Situacao_Profissional.pdf?sequence=4>.

ROSA, M. Situação do professorado em Portugal - identidades fragmentadas entre a paixão e o desencanto. Educação, Porto Alegre, RS, v. 39, n. 3, p. 412-420, set./dez. 2016b. 
ROSA, M. Representações dos professores de Educação Física na inclusão de alunos com Necessidades Educativas Especiais. 2005. Dissertação (Mestrado em Psicologia da Educação) - Universidade do Algarve, Faro, Portugal, 2005. Disponível em: <https://sapientia.ualg.pt/ bitstream/10400.1/1714/1/Disserta\%C3\%A7\%C3\%A3o_marcorosa\%2034.pdf >.

SANTOS, B. Renovar a teoria crítica e reinventar a emancipação social. São Paulo: Boitempo, 2007.

STOLEROFF, A. The revolution in the public services sector in Portugal: with or without the unions. Transfer, v. 13, n. 4, p. 631-652, 2007.

\section{Sobre o autor:}

Marco Corriente Rosa: Doutorado em Educação pela Universidade de Huelva (Espanha). E-mail: marcocorriente@gmail.com

Recebido em março de 2017.

Aprovado para publicação em abril de 2017. 
